\title{
Customers' Switching Intention among Smartphone Brands
}

\author{
Yi Hsu \\ Associate Professor \\ Department of Business Administration \\ National Formosa University, Huwei, Yunlin \\ Taiwan \\ Manhdat Nguyen \\ Graduate Student, \\ Department of Business Administration \\ National Formosa University, Huwei, Yunlin \\ Taiwan
}

\begin{abstract}
Witnessing the unprecedented development and high competition in smartphone industry, the study aims to explore the factors affecting customers' switching intention among smartphone brands. Based on literature review of previous researches, a research model was built with constructs, namely switching intention, product quality, service quality, relationship quality, switching cost, inertia, perceived price, and using habit. A survey was conducted and 482 samples were collected for data analysis process. By applying LISREL, this study shows service quality, relationship quality, and inertia as expected, negatively influence customers' switching intention, while product quality and switching cost have insignificant influence. In addition, besides switching cost and using habit, perceived price as a newly-suggested antecedent positively influences inertia.
\end{abstract}

Keywords: Switching Intention, Inertia, Perceived Price, LISREL, Smartphone.

\section{Introduction}

Since the first appearance in 1992, smartphone has been developed from an expensive device to become a daily used gadget. Smartphone is described as high-end cell phone, an electronic device with up-to-date hardware, Internetconnecting ability, powerful operating system, intuitive user interfaces and functional applications that provides users a large range of features (Oulasvirta, Wahlstrom, and Ericsson, 2011). Indeed, nowadays, smartphones appear as fullyfunctional PCs, which in particular, include special features such as wireless internet connection, mobile multimedia ability, web-browsers, software applications, data storage capability up to hundreds GBs, high display resolution screen and so on. Due to its convenience, it is understandable to witness the huge growth in the use of smartphones in the recent years.

According to www.statista.com, during the period from 2007 to 2018, the worldwide sales quantity of smartphone devices to end users has increased rapidly year by year, from 122.32 million devices in 2007 to 1555.27 million devices in 2018. The development of the smartphones market is still expected to continue in the future with the annual average growth rate of $3.00 \%$ until 2021. In particular, the smartphone devices shipment is predicted to reach 1642.3 million units in 2019 and keep increasing to 1710.1 million in 2021.

As a thriving industry, it is high competition within the smartphone market. In the 2000s, Nokia was the global leader in the cell phone market, however in the 2010s, the market witnessed huge change when Nokia was acquired partly by Microsoft, while Samsung and Apple merged as the first and second leader, in terms of the market share. Nowadays, though Samsung still remains its position in the smartphone market, this South Korean brand confronts serious competition or even loses market share in some areas to other emerging competitors, such as Huawei, Xiaomi or OPPO. Many rivals provide more offers for customers in this profitable industry. Therefore, it is reasonable for customers to switch among smartphone brands. Thus, business can obtain more customers or lose their existing customers. Customers' switching intention is always considered as an important factor in highly competitive industry, since firms may utilize it to evaluate their strength and weakness. Understanding the essential of customers' switching intention to business, the study aims on researching the main factors which may significantly impact customers' switching intention. Moreover, the study also provides some contributions in both practical and theoretical aspects. 
The first section introduces the smartphone devices, smartphone markets, research purposes, and research structure. The other sections are literature review, methodology, results and discussion. Literature review presents related previous researches' findings, definition of all constructs, namely, switching intention, product quality, service quality, inertia, relationship quality, switching cost, perceived price and using habit. This part also develops the ten hypotheses which are tested in the study. The third section introduces the conceptual model and methodology. In particular, it provides information about conducted survey, questionnaire development, data analysis. The fourth section presents the data analysis results, hypotheses testing results and construct LISREL model. The fifth section summarizes main findings and some implications. Limitations and further potential research are also mentioned in this part.

\section{Literature review}

\subsection{Switching Intention}

Switching intention is intention from customers to cease using current brands and exchange to others (Bansal and Taylor, 1999). Therefore, switching intention is also understood as contrary to the concept of customer loyalty and may have two possible consequences to a business. Customers' switching among brands can help switched business get more customers; otherwise it can also cause the loss of current customers to switching business.

\subsection{Product Quality}

Product quality was described as the conformity to each customer individual requirements or specifications (Reeves and Bednar, 1994). The feeling of enjoyment, pleasure, content and satisfaction can be triggered by high degree of product quality, which may make customer confident, trusted in current brands, hence weaken switching intention. Therefore, the study develops the first hypothesis as: H1. Product quality negatively influences customers' switching intention.

\subsection{Service Quality}

Service quality is the overall judgement of service superiority from customers (Parasuraman, Zeithaml, and Berry, 1985). In fact, customers who assess service quality as high have the possibility of repurchase due to high satisfaction and brand loyalty, while customers who evaluate service quality as low are likely to change to other brands. Therefore, the study developed the second hypothesis as: H2: Service quality negatively influences customers' switching intention.

\subsection{Relationship Quality}

Relationship quality is the reliable relationship with the customers, relationship quality decreases the customer uncertainty for transacting and increases customer loyalty, therefore customers may become positively response or reliant towards services or products brands (Smith, 1998) The concept of relationship quality, in fact has been reviewed by many previous researches. Most of researches agree with the three dimensions of relationship quality, which include: customer satisfaction, commitment, and trust. This study also follows the previous researches with this three-dimension relationship quality. Satisfaction is positive emotion after using service or products (Um, Chon, and Ro, 2006). Obviously, this emotional status is expected by service or product provider because it enhances the customer loyalty which leads to repurchase intention or prevent switching intention. Moreover, Bansal and Taylor's study (1999) also figured out customer satisfaction negatively influenced customers' switching intention. Customer trust as customer beliefs relating certain characteristics of supplier (Coulter and Coulter, 2002). Customer commitment is the enduring expectation to retain a relationship due to good previous performance of service or product providers (Palmatier, Dant, Grewal, and Evans, 2006). Therefore, trust and commitment can encourage customer to repurchase, enhance customer loyalty and deteriorate switching intention.

Following the previous researches, three hypotheses are developed as:

H3: Customer satisfaction negatively influences customers' switching intention.

H4: Trust negatively influences customers' switching intention.

H5: Commitment negatively influences customers' switching intention.

\subsection{Switching Cost}

Switching cost was described as the cost that users; or customers have to bear if they decide to stop using current service or products and switch to other brands (Burnham, Freds, and Mahajan, 2003). There have already been a number of researches about switching cost and switching cost's types. A majority of researches have agreed with and paid high attention to continuity cost, sunk cost and set-up cost, three major switching cost. Continuity costs are considered as opportunity cost because after years of continuously using the same brand, the customers may attain special benefits if they keep using the current brand. The decision of switching to other brands can cause the customer loss of these particular interests. Sunk costs is the costs which include time, effort and expense that have been spent on current brands (Chang, Liu, and Chen, 2014). 
Finally, set-up costs are described as the time, effort, and money invested to use new service or product (Burnham et al., 2003). Previous studies found out switching cost negatively impact customers' switching intention such as Chang et al. (2014), increasing switching costs deteriorates the switching intention. Consequently, the sixth hypothesis of this study is developed as: H6: Switching cost negatively influences the customers' switching intention.

\subsection{Inertia}

Inertia is customer current behavioral patterns, though better incentives to switch are available (Polites and Karahanna, 2012). Moreover, inertia also reduces sense of the ease of use or attractiveness, appeal of substitute and negatively influences customers' intention to chance, hence the following hypothesis is developed as: H7: Inertia negatively influences the customers' switching intention.

\subsection{Antecedents of inertia}

\subsubsection{Switching Cost}

If the switching cost is higher in comparison with switching benefits, inertia may decrease the customers' switching intention (Sun, Liu, Chen, Shen, and Zhang, 2017). In particular, for sunk cost, inertia appears when customers notice their previously invested time, money, and effort in current brands as high; for set up cost, users may hesitate to switch if they perceive spending time, money, and effort in initiating new brand is not necessary; and continuity costs may result in inertia, if customers maintain the current brand because they may attain particular advantages, regardless of better alternatives (Sun, et al., 2017). Therefore, the study proposes the eighth hypothesis as: H8: Switching cost positively influences inertia.

\subsubsection{Perceived Price (of alternatives)}

From customer perspective, price is described as the sum of money that consumers have to pay to obtain service or products (Zeithaml, 1988). In the smartphone market, price can be barrier for customers when they want to purchase new products or switch to other brands. Like other industry, smartphone market is also divided into small segments based on selling price. Customers may realize the advantages, benefits and superior functions of alternative products or brands, however high perceived price of alternatives forces them to maintain current products or brands instead of purchase new ones or switch to other brands. Therefore, the study develops the following hypothesis as: H9: Perceived price positively influences inertia.

\subsubsection{Using Habit}

Habit is sequences of actions which people do frequently, automatically, and almost without much thinking (Aarts, 1999). If customers have the habit of using a certain brand, they are unlikely to make comparison among brands, in fact, they simply take spontaneous action to follow their current behavior patterns, which reduce the cost of individual decision making (Sun et al., 2017). Moreover, customers who expect to avoid changing stress, and switching feel comfortable to stick to current brands, which leads to inertia. Hence, the study proposes the tenth hypothesis as: H10: Using habit positively influences inertia.

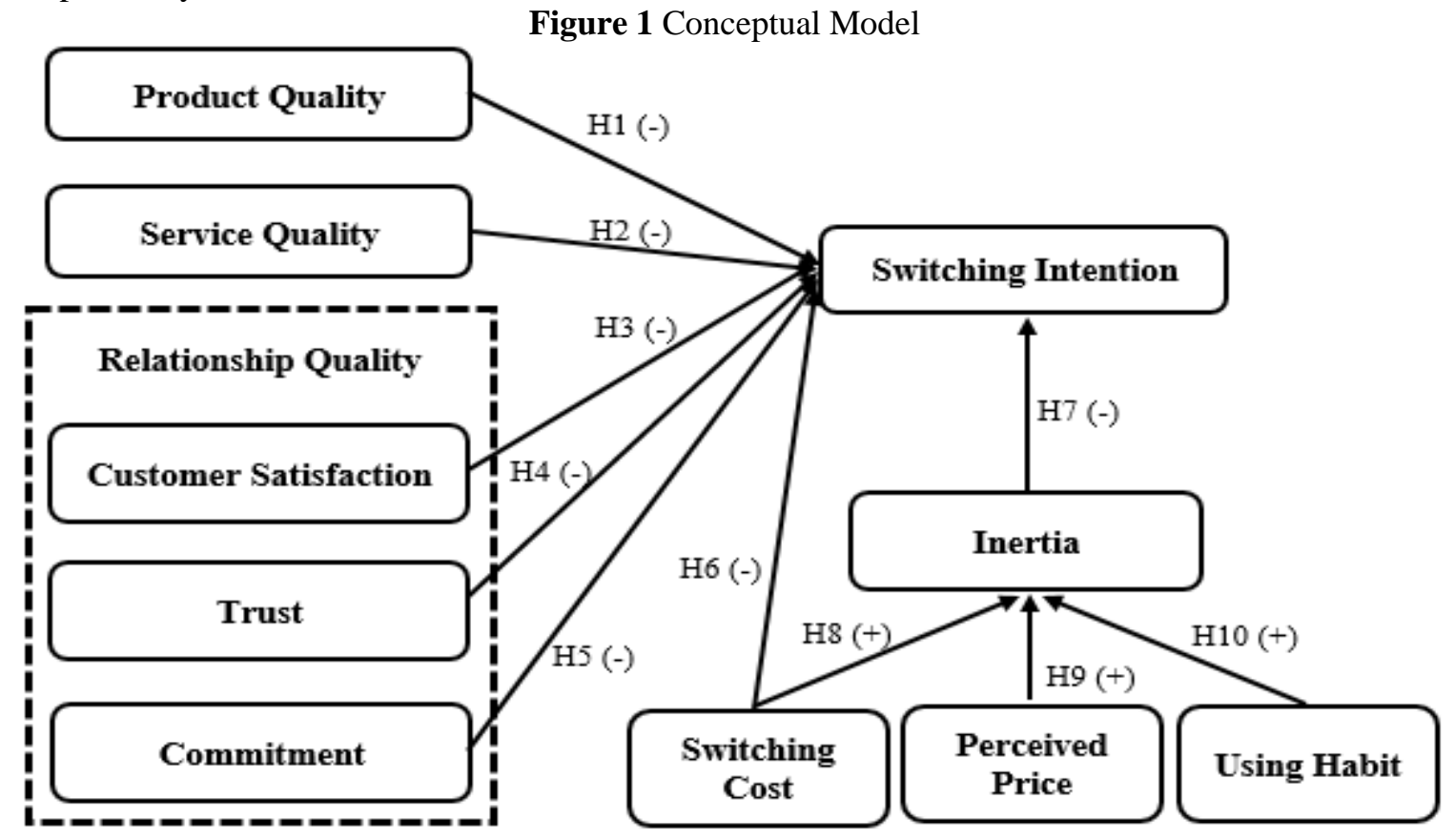




\section{Methodology}

In this study, LISREL software (ver 8.8) and STATISTICA software (ver 10.0) were utilized for data analysis. For testing the ten hypotheses in the research model (Figure 1), data analysis process was conducted with two major stages. Firstly, the study clarified the measurement scale, secondly the relationship between variables was evaluated.

\subsection{Constructs measurement and data collection}

To get the insight understanding of the customers' intention of switching among smartphones brands and test the proposed conceptual model, survey research method was conducted. This survey includes two parts. The first part with 48 five-point Likert-type scale questions measures the variables namely customers' switching intention, product quality, service quality, customer satisfaction, trust, commitment, switching cost, inertia, perceived price, and using habit. The second part includes 11 demographic questions to get a deeper knowledge of respondents.

In order to gain data, a survey with English, Vietnamese and Chinese version was conducted from Sep $09^{\text {th }} 2018$ to Nov $15^{\text {th }} 2018$. The survey was distributed online through Google Forms and other social network platforms. A total of 482 responds were collected and valid for further processing.

\subsection{Data Analysis}

\subsubsection{Exploratory factor analysis (EFA)}

In multivariate exploratory technique, this study conducted Principal Axe factor analysis to retrench the variables and confirmatory factor analysis is utilized to construct the LISREL model to explain the relationships among variables. Among the rotation methods, Oblique rotation method, Varimax normalized rotation was also selected for retrenching the variables. For factor loadings, in general, the higher the factor loadings is, the better validity is, but Hair, Black, Babin, Anderson, and Tatham (2014) mentioned 0.5 as the cut-off for practical significance. After exploratory factor analysis, 46 out of 48 question of the study were remained and loaded into 10 factors.

\subsubsection{Confirmatory factor analysis (CFA)}

In general, CFA is conducted to take a confirmatory test. Unlike EFA, in CFA, all factors are developed from theory, instead of statistical results, which means before analysis, researchers should clearly understand the number of constructs, variables and which constructs each variable belong to.

\subsubsection{Linear structural relations (LISREL)}

To test the hypotheses, the LISREL software was utilized. The program, which has been popularly used to estimate covariance structure models, combines the features of both factor analysis and multiple regression. In addition, fit indices such as: Chi-square/d.f, RMR and RMSEA (absolute fit indices), CFI (incremental fit index) are computed and considered adequate to assess model fit (Hair et al., 2014).

\section{Result}

\subsection{Demographic statistics}

Table 1 shows details about demographic information of respondents. As can be seen, males account for $59.9 \%$ with 289 samples while females make up $40.1 \%$ with 193 samples. Regarding marital status, singles make up $77.2 \%$ and married people constitute 22.8\%. Most of samples are from Vietnam and Taiwan, $48.1 \%$ and $40.9 \%$ respectively and only 55 samples (11\%) are from other countries such as: Mongolia, Thailand, Indonesia, and India. In term of age, age group from 18 to 25 takes the majority with 245 samples (50.8\%), followed by age group 26-35 with 186 samples (38.6\%) and age group 36-45 with 48 samples (10\%). Only 3 samples are under 18 year-old, while no respondent is over 45 year-old. Regarding smartphone brands, Samsung and Apple take the first and second place with 38.8\% and $24.9 \%$ respectively. A majority of samples (71\%) have average monthly income between USD 250-1000. 
Table 1. Demographic Statistics

\begin{tabular}{llllll}
\hline Items & Frequency & Percentage (\%) & Items & Frequency & Percentage (\%) \\
\hline Gender & & \multicolumn{5}{l}{ Nationality } & & \\
\hline Male & 289 & 59.9 & Vietnam & 232 & 48.1 \\
Female & 193 & 40.1 & Taiwan & 197 & 40.9 \\
& & & Other & 53 & 11 \\
\hline Age & & Monthly Income & \\
\hline$<18$ & 3 & 0.6 & <USD250 & 51 & 10.6 \\
$18-25$ & 245 & 50.8 & USD251-500 & 169 & 35.1 \\
$26-35$ & 186 & 38.6 & USD501-1000 & 173 & 35.9 \\
$36-45$ & 48 & 10 & >USD1000 & 89 & 18.4 \\
\hline Smartphone Brand & & Martial Status & \\
\hline Apple & 120 & 24.9 & Single & 372 & 77.2 \\
Samsung & 187 & 38.8 & Married & 110 & 22.8 \\
Other & 92 & 36.3 & & & \\
\hline
\end{tabular}

\subsection{Confirmatory factor analysis (CFA)}

Table 2 presents in details the CFA results. Some items were deleted because of low factor loading, others were deleted to increase the model fit. All remained items have factor loading over the recommended number of 0.5. Besides, for reliability, Fornell and Larcker (1981) suggested 0.7 as the cut-off value for Cronbach's alpha. The result showed all constructs had suitable Cronbach's alpha value. In Table 3, the covariance matrix presents the linear relationship between constructs.

Table 2

CFA items and loading

\begin{tabular}{|c|c|c|c|c|c|}
\hline Constructs Items & Factor loading & Cronbach's alpha & Constructs Items & Factor loading & Cronbach's alpha \\
\hline \multicolumn{2}{|c|}{ Switching Intention } & 0.950 & Commitment & & 0.940 \\
\hline SI1 & 0.92 & & COM1 & 0.69 & \\
\hline SI2 & 0.86 & & $\mathrm{COM} 2$ & 0.72 & \\
\hline SI3 & 0.89 & & COM3 & 0.72 & \\
\hline SI4 & 0.9 & & COM4 & 0.7 & \\
\hline SI5 & 0.89 & & & & \\
\hline \multicolumn{2}{|l|}{ Product Quality } & 0.970 & Switching Cost & & 0.770 \\
\hline PQ1 & 0.82 & & $\mathrm{SC} 1$ & 0.92 & \\
\hline PQ2 & 0.8 & & $\mathrm{SC} 2$ & 0.86 & \\
\hline PQ3 & 0.79 & & $\mathrm{SC} 3$ & 0.86 & \\
\hline PQ4 & 0.77 & & $\mathrm{SC} 4$ & 0.9 & \\
\hline PQ5 & 0.79 & & & & \\
\hline PQ6 & 0.88 & & & & \\
\hline \multicolumn{2}{|l|}{ Service Quality } & 0.940 & Inertia & & 0.960 \\
\hline SQ1 & 0.58 & & IN1 & 0.68 & \\
\hline SQ2 & 0.69 & & IN2 & 0.55 & \\
\hline SQ3 & 0.61 & & IN3 & 0.62 & \\
\hline \multirow[t]{2}{*}{ SQ4 } & 0.84 & & IN4 & 0.64 & \\
\hline & & & IN5 & 0.52 & \\
\hline \multicolumn{2}{|c|}{ Customer Satisfaction } & 0.930 & Perceived Price & & 0.850 \\
\hline $\mathrm{CS} 1$ & 0.81 & & PP1 & 0.78 & \\
\hline $\mathrm{CS} 2$ & 0.77 & & PP2 & 0.8 & \\
\hline $\mathrm{CS} 3$ & 0.8 & & PP3 & 0.88 & \\
\hline CS4 & 0.76 & & PP4 & 0.57 & \\
\hline CS5 & 0.81 & & & & \\
\hline CS6 & 0.86 & & & & \\
\hline \multicolumn{2}{|l|}{ Trust } & 0.880 & Using Habit & & 0.750 \\
\hline TRU1 & 0.87 & & UH1 & 0.89 & \\
\hline TRU2 & 0.83 & & UH2 & 0.83 & \\
\hline TRU3 & 0.84 & & UH3 & 0.84 & \\
\hline TRU4 & 0.81 & & UH4 & 0.84 & \\
\hline
\end{tabular}


Table 3 Covariance Matrix

\begin{tabular}{|c|c|c|c|c|c|c|c|c|c|c|}
\hline & SI & PQ & SQ & CS & TRU & COM & SC & IN & PP & UH \\
\hline SI & 1.76 & & & & & & & & & \\
\hline PQ & -0.23 & 1.19 & & & & & & & & \\
\hline SQ & -0.10 & 0.03 & 0.59 & & & & & & & \\
\hline CS & -0.38 & 0.91 & 0.06 & 1.72 & & & & & & \\
\hline TRU & -0.41 & 0.45 & 0.03 & 0.67 & 1.52 & & & & & \\
\hline COM & -0.47 & 0.25 & 0.03 & 0.04 & 0.47 & 1.07 & & & & \\
\hline SC & -0.19 & 0.11 & 0.01 & 0.15 & 0.19 & 0.23 & 1.75 & & & \\
\hline IN & -0.17 & 0.08 & -0.03 & 0.13 & 0.14 & 0.16 & 0.13 & 0.35 & & \\
\hline PP & -0.35 & 0.19 & 0.02 & 0.39 & 0.40 & 0.31 & 0.31 & 0.31 & 1.41 & \\
\hline UH & -0.28 & 0.27 & 0.02 & 0.40 & 0.37 & 0.43 & 0.12 & 0.1 & 0.18 & 1.56 \\
\hline
\end{tabular}

* SI-switching intention, PQ-product quality, SQ-service quality, CS-customer satisfaction, TRU-trust, COMcommitment, SC-switching cost, IN-inertia, PP-perceived price, UH-using habit

\subsection{Test of hypotheses}

The LISREL result was shown in Figure 2 and Table 4. Contrary to the research expectation, product quality (t-value $=-0.12, \mathrm{p}>0.05)$, customer satisfaction $(\mathrm{t}$-value $=-1.24, \mathrm{p}>0.05)$, and switching cost $(\mathrm{t}-\mathrm{value}=-0.73, \mathrm{p}>0.05)$ have insignificant influences on customers' switching intention. Therefore, H1, H3, and H6 are unsupported. Service quality $(\beta=-0.24, \mathrm{t}$-value $=-2.58, \mathrm{p}<0.05)$, trust $(\beta=-0.11, \mathrm{t}$-value $=-2.10, \mathrm{p}<0.05)$, commitment $(\beta=-0.31, \mathrm{t}$-value $=-5.15$, $\mathrm{p}<0.05)$, and inertia $(\beta=-0.30$, t-value $=-3.06, p<0.05)$ have significant negative influences on customers' switching intention. $\mathrm{H} 2, \mathrm{H} 4, \mathrm{H} 5$, and $\mathrm{H} 7$ are supported. Finally, switching cost $(\beta=0.07$, t-value $=2.11, \mathrm{p}<0.05)$, perceived price $(\beta=0.21$, t-value $=5.85, \mathrm{p}<0.05)$, and using habit $(\beta=0.04, \mathrm{t}$-value $=2.00, \mathrm{p}<0.05)$ are tested to positively influence inertia. Therefore, $\mathrm{H} 8, \mathrm{H} 9$, and $\mathrm{H} 10$ are supported.

Figure 2 Result of LISREL

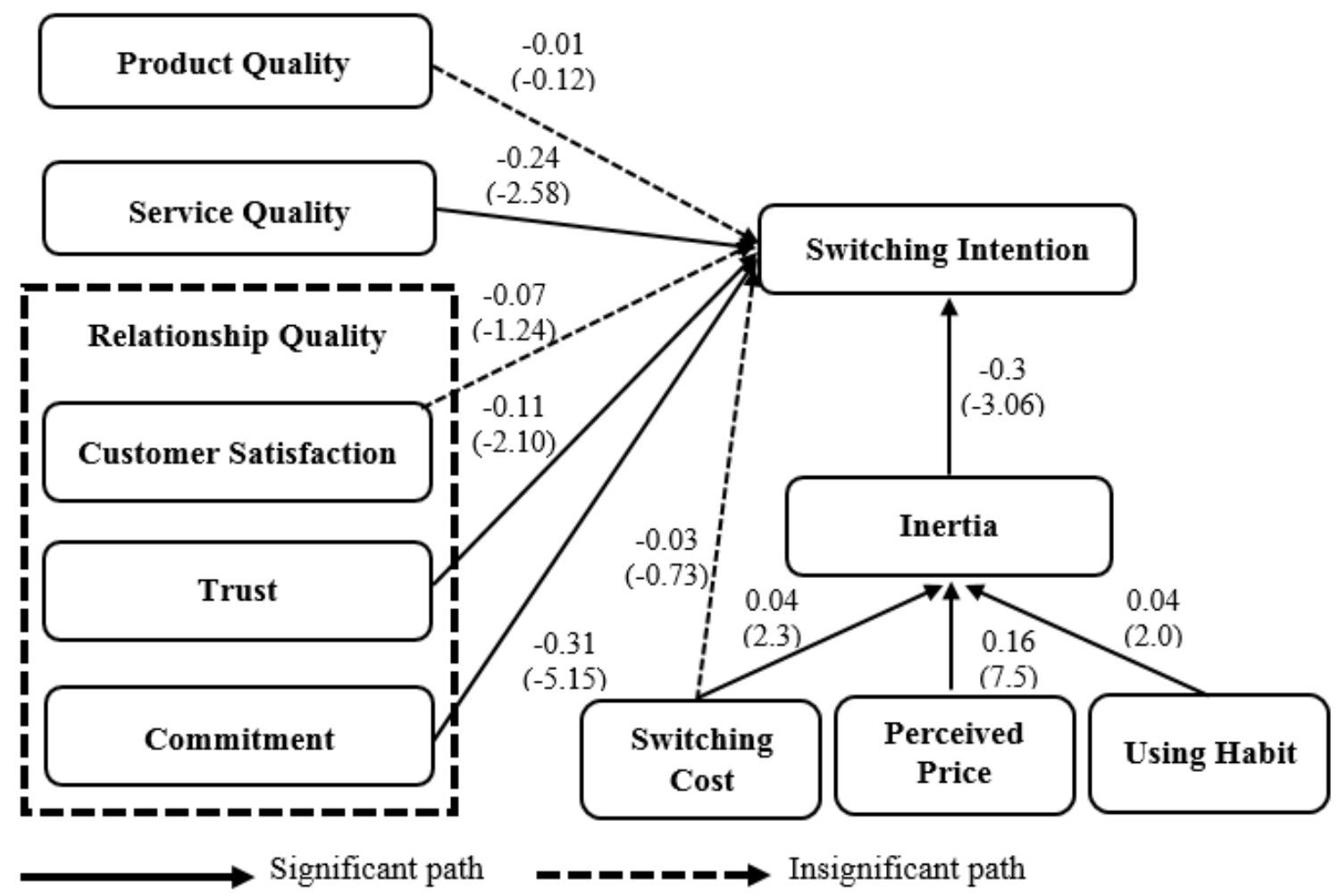

Chi square $=19.92, \mathrm{df}=7, \mathrm{P}$-value $=0.0574, \mathrm{RMSEA}=0.062, \mathrm{GFI}=0.99$ 


\section{Table 4}

Hypotheses testing

\begin{tabular}{lllll}
\hline Hypothesis & Estimates & t-value & $\begin{array}{l}\text { Supported } \\
\text { (Yes/No) }\end{array}$ \\
\hline H1 & Product Quality $\rightarrow$ Switching Intention & -0.01 & -0.12 & No \\
H2 & Service Quality $\rightarrow$ Switching Intention & -0.24 & -2.58 & Yes \\
H3 & Customer Satisfaction $\rightarrow$ Switching Intention & -0.07 & -1.24 & No \\
H4 & Trust $\rightarrow$ Switching Intention & -0.11 & -2.1 & Yes \\
H5 & Commitment $\rightarrow$ Switching Intention & -0.31 & -5.15 & Yes \\
H6 & Switching Cost $\rightarrow$ Switching Intention & -0.03 & -0.73 & No \\
H7 & Inertia $\rightarrow$ Switching Intention & -0.3 & -3.06 & Yes \\
H8 & Switching Cost $\rightarrow$ Inertia & 0.04 & 2.3 & Yes \\
H9 & Perceived Price $\rightarrow$ Inertia & 0.16 & 7.5 & Yes \\
H10 & Using Habit $\rightarrow$ Inertia & 0.04 & 2.0 & Yes \\
\hline
\end{tabular}

For fit index, the most important criteria namely, Chi-square $/ \mathrm{df}=2.84, \mathrm{CFI}=0.988, \mathrm{GFI}=0.99, \mathrm{AGFI}=0.935, \mathrm{RMR}=$ 0.021 , and RMSEA $=0.062$, all meet the recommended standard. In particular, Hair et al. (2014) suggested Chisquare/df should be under 3; CFI, GFI, and AGFI should be over 0.9; RMSEA and RMR should be under 0.08 for good model fit. Therefore, the study gets enough sufficient information to conclude the model has good fit-indexes.

\section{Discussion}

\subsection{Summary of result}

With the unprecedented development and high competition in the smartphone industry, understanding the determinants of customers' switching intention among smartphone brands is essential. Researching customers' switching intention toward smartphone brands is, therefore, the key purposes of this paper. Firstly, service quality, relationship quality (trust, commitment included), and inertia negatively influence customers' switching intention. Moreover, in this study, relationship quality appears as the most powerful factor that causes customers to maintain their current smartphone brands. This finding is understandable because when customers trust a supplier or feel committed to a brand, they would be more loyal to this brand and unlikely to switch. In addition, if customers receive high service quality from smartphone brands and suppliers or have inertia, they are likely to stay within current brands, instead of changing to alternatives. Secondly, product quality, customer satisfaction, and switching cost were expected to impact customers' switching intention; however the study shows opposite results. The hypotheses are unsupported. It is quite amazing that product quality and customer satisfaction which are generally thought to influence customers' switching intention, appear to have insignificant influence on customers' switching intention. It is maybe due to the fact that nowadays the quality gap between different smartphone producers is small because of technology development and technology transfer. For switching cost, this finding is contradict to some previous researches. Thirdly, all three inertia antecedents, namely switching cost, perceived price, and using habit positively influence inertia. Potential reasons is the fact that the switching cost that customers have to bear if they decide to switch to other brands and perceived price of others are too expensive to change, regardless of clear advantages, attractiveness of alternative products or brands.

\subsection{Theoretical implications}

The study contributes some theoretical implications. Firstly, this study was one among a few studies which conducted a thorough research to understand customers' switching intention in smartphone industry. Secondly, the study proposed inertia as a main structure which has influence on switching intention. Inertia, which has been frequently used to indicate preference to keep using current products/service regardless of better options, is not new in previous researches to explain how new technologies is accepted, however the function in switching intention has seldom been studied. Thirdly, in addition to switching cost and using habit which have already been examined in many previous researches, the study proposed perceived price as another antecedent. This finding enriches the understanding of inertia components.

\subsection{Practical implications}

For practical implications, the study provides some useful information for management purposes. Firstly, as a major factor which has negative impact on customers' switching intention, relationship quality should be paid high attention. Hence, marketing functions may develop suitable campaign to gain customer trust and commitment, which enhance customer brand loyalty to keep using the current smartphone brands. Besides relationship quality, service quality also takes a key role in preventing switching intention. Therefore, service providers should also focus on service quality by working closely with retailers, retail staff, and supply chains to maintain high quality and retain existing customers. 
Secondly, although the results reveals insignificant relationship between product quality, customer satisfaction, switching cost, and switching intention, it does not signify these factors can be ignored. In fact, more research should be conducted for more understanding. Meanwhile, smartphone producers and suppliers still need to assure high product quality, customer satisfaction, and maintain suitable policy to gain customer loyalty. Thirdly, because switching cost, perceived price, and using habit have positive impact on inertia, marketing function should have reasonable price strategy and other promotion campaigns.

\subsection{Limitations and further research}

Firstly, although the study expected to gain larger samples sizes with more diversity in all demographic aspects such as age, occupations, nationalities, and income ranges, most of samples are Vietnamese, Taiwanese students or employees at the age between 18 and 36. However, due to the fact that target customers of smartphone industry are young people, the sample with majority of young respondents is accepted. Secondly, as mentioned above, switching intention have two potential results, one is helping business recruit more customers, and another is losing existing customers. The study just focused on product quality, service quality, customer satisfaction, relationship quality, and inertia, which are proposed to have negative impact on switching intention. It means the study just stands on one side of researching the factors which help to maintain current customers. Therefore, further studying should be conducted to explore the factors which support business to recruit more customers such as attractiveness of alternative, need for variety, subjective norm, and social influence.

\section{References}

Aarts, H. (1999). Habit, attitude, and planned Behaviour: Is habit an empty construct or an interesting case of goaldirected automaticity? European Review of Social Psychology, 10(1), 101e134.

Bansal, H. S., \& Taylor, S. F. (1999). The service provider switching model (SPSM). Journal of Service Research, 2(2), 200e218.

Burnham, T. A., Frels, J. K., \& Mahajan, V. (2003). Consumer switching costs: a typology, antecedents, and consequences. Journal of the Academy of marketing Science, 31(2), 109-126.

Chang, I., Liu, C. C., \& Chen, K. (2014). The push, pull and mooring effects in virtual migration for social networking sites. Information Systems Journal, 24(4), 323e346.

Coulter, K. S., \& Coulter, R. A. (2002). Determinants of trust in a service provider: the moderating role of length of relationship. Journal of services marketing, 16(1), 35-50.

Fornell, C., \& Larcker, D. F. (1981). Evaluating structural equation models with unobservable variables and measurement error. Journal of Marketing Research, 18(1), 39e50.

Hair, J. F., Black, W. C., Babin, B. J., Anderson, R. E., \& Tatham, R. L. (2014). Multivariate data analysis 7th Edition, New Jersey, Person Education Limited.

Oulasvirta, A., Wahlström, M., \& Ericsson, K. A. (2011). What does it mean to be good at using a mobile device? An investigation of three levels of experience and skill. International journal of human-computer studies, 69(3), 155-169.

Palmatier, R. W., Dant, R. P., Grewal, D., \& Evans, K. R. (2006). Factors influencing the effectiveness of relationship marketing: a meta-analysis. Journal of marketing, 70(4), 136-153.

Parasuraman, A., Zeithaml, V. A., \& Berry, L. L. (1985). A conceptual model of service quality and its implications for future research. Journal of marketing, 49(4), 41-50.

Polites, G. L., \& Karahanna, E. (2012). Shackled to the Status Quo: The Inhibiting Effects of Incumbent System Habit, Switching Costs, and Inertia on New System Acceptance. MIS Quarterly, 36(1), $21 \mathrm{e} 42$.

Reeves, C. A., \& Bednar, D. A. (1994). Defining quality: alternatives and implications. Academy of management Review, 19(3), 419-445.

Smith, B. (1998). Buyer-seller relationships: bonds, relationship management, and sex-type. Canadian Journal of Administrative Sciences/Revue Canadienne des Sciences de l'Administration, 15(1), 76-92.

Statista, (2018, December), Global smartphone shipments forecast from 2010 to 2022 (in million units). Retrieved from https://www.statista.com

Statista, (2019, February), Number of smartphone sold to end users worldwide from 2007 to 2019 (in million units). Retrieved from https://www.statista.com

Sun, Y., Liu, D., Chen, S., Wu, X., Shen, X. L., \& Zhang, X. (2017). Understanding users' switching behavior of mobile instant messaging applications: An empirical study from the perspective of push-pull-mooring framework. Computers in Human Behavior, 75, 727-738.

Um, S., Chon, K., \& Ro, Y. (2006). Antecedents of revisit intention. Annals of tourism research, 33(4), 1141-1158.

Zeithaml, V. A. (1988). Consumer perceptions of price, quality, and value: a means-end model and synthesis of evidence. Journal of marketing, 52(3), 2-22. 